\title{
Plastic response to early shade avoidance cues has season-long effect on Beta vulgaris growth and development
}

\author{
Albert Adjesiwor ${ }^{1}$, Joseph Ballenger ${ }^{1}$, Cynthia Weinig ${ }^{1}$, Brent E. Ewers ${ }^{1}$, and Andrew \\ Kniss $^{1}$ \\ ${ }^{1}$ University of Wyoming
}

November 26, 2020

\begin{abstract}
Early emerging weeds are known to negatively affect crop growth but the mechanisms by which weeds reduce crop yield are not fully understood. In a 4-yr study, we evaluated the duration of weed-reflected light on sugar beet (Beta vulgaris L.) growth and development. The study included an early-season weed removal series and a late-season weed addition series of treatments arranged in a randomized complete block, and the study design ensured minimal direct resource competition. If weeds were present from emergence until the two true-leaf sugar beet stage, sugar beet leaf area was reduced $22 \%$, leaf biomass reduced $25 \%$, and root biomass reduced $32 \%$ compared to sugar beet grown season-long without surrounding weeds. Leaf area, leaf biomass, and root biomass were similar whether weeds were removed at the two true-leaf stage (approximately 330 GDD after planting) or allowed to remain until sugar beet harvest (approximately 1240 GDD after planting). Adding weeds at the two true-leaf stage and leaving them until harvest ( $~ 1240$ GDD) reduced sugar beet leaf and root biomass by 18 and $23 \%$, respectively. It appears sugar beet responded to weed presence by adjusting carbon allocation and leaf orientation to optimize light interception.
\end{abstract}

Title page:

1. Title: Plastic response to early shade avoidance cues has season-long effect on Beta vulgaris growth and development

2. Authors: Albert T. Adjesiwor ${ }^{1}$, Joseph G. Ballenger ${ }^{1}$, Cynthia Weinig $^{2}$, Brent Ewers ${ }^{2}$, Andrew R. $\mathrm{Kniss}^{1 *}$

3. Contact Information: Department of Plant Sciences, University of Wyoming, Laramie, WY, 82071 USA; ${ }^{2}$ Department of Botany, University of Wyoming, Laramie, WY 82071 USA;A.T. Adjesiwor's present address: University of Idaho, Kimberly Research and Extension Center, Kimberly, ID, 83341; *Corresponding author: Andrew R. Kniss (akniss@uwyo.edu).

4. Funding: Funding for this research was provided by United States Department of Agriculture - National Institute of Food and Agriculture grant 2016-67013-24912, and by the Western Sugar CooperativeGrower Joint Research Committee.

5. Abstract: Early emerging weeds are known to negatively affect crop growth but the mechanisms by which weeds reduce crop yield are not fully understood. In a 4-yr study, we evaluated the effect of duration of weed-reflected light on sugar beet (Beta vulgarisL.) growth and development. The study included an early-season weed removal series and a late-season weed addition series of treatments arranged in a randomized complete block, and the study design ensured minimal direct resource competition. If weeds were present from emergence until the two true-leaf sugar beet stage, sugar beet leaf area was reduced $22 \%$, leaf biomass reduced $25 \%$, and root biomass reduced $32 \%$ compared to sugar beet grown season-long without surrounding weeds. Leaf area, leaf biomass, and root biomass was similar whether weeds were removed at the two true-leaf stage (approximately 330 GDD after planting) or allowed to remain until sugar beet harvest (approximately 1240 GDD after planting). Adding 
weeds at the two true-leaf stage and leaving them until harvest ( $\sim 1240$ GDD) reduced sugar beet leaf and root biomass by 18 and $23 \%$, respectively. It appears sugar beet responded to weed presence by adjusting carbon allocation and leaf orientation to optimize light interception.

6. Keywords: environmental plasticity; light quality; shade avoidance; weed competition; weed removal timing; yield potential

7. Acknowledgments: The authors thank David Claypool who helped with the study establishment, harvesting, and processing.

Summary StatementThe presence of weed-reflected light during sugar beet emergence through the two true-leaf stage $(\sim 16 \mathrm{~d}$ after emergence) had a more detrimental impact on crop growth than the same environmental cue beginning at the two true-leaf stage until harvest $50 \mathrm{~d}$ later. Sugar beet responded irreversibly to the presence of early-season weed presence, and therefore shade avoidance may be a major contributor to sugar beet yield loss due to weeds.

\section{Main Text File:}

Plastic response to early shade avoidance cues has season-long effect on Beta vulgaris growth and development

Abstract: Early emerging weeds are known to negatively affect crop growth but the mechanisms by which weeds reduce crop yield are not fully understood. In a 4-yr study, we evaluated the duration of weed-reflected light on sugar beet (Beta vulgaris L.) growth and development. The study included an early-season weed removal series and a late-season weed addition series of treatments arranged in a randomized complete block, and the study design ensured minimal direct resource competition. If weeds were present from emergence until the two true-leaf sugar beet stage, sugar beet leaf area was reduced $22 \%$, leaf biomass reduced $25 \%$, and root biomass reduced $32 \%$ compared to sugar beet grown season-long without surrounding weeds. Leaf area, leaf biomass, and root biomass were similar whether weeds were removed at the two true-leaf stage (approximately 330 GDD after planting) or allowed to remain until sugar beet harvest (approximately 1240 GDD after planting). Adding weeds at the two true-leaf stage and leaving them until harvest ( 1240 GDD) reduced sugar beet leaf and root biomass by 18 and $23 \%$, respectively. It appears sugar beet responded to weed presence by adjusting carbon allocation and leaf orientation to optimize light interception.

Keywords: environmental plasticity; light quality; shade avoidance; weed competition; weed removal timing; yield potential

\section{Introduction}

Plants are exposed to heterogenous environments comprising different levels of stress and competition for resources. As sessile organisms, plants often exhibit morphological plasticity in response to adverse environmental conditions. Many of these responses involve developmental trade-offs that affect plant growth and development and their ability to respond to future environmental cues (Page, Tollenaar, Lee, Lukens, \& Swanton, 2010; Weinig \& Delph, 2001).

Mechanisms described as optimality, balanced growth, or functional equilibrium suggest that plants allocate more resources to the organ(s) which is(are) acquiring the resource that is currently the most limiting (Gedroc, McConnaughay, \& Coleman, 1996; Poorter et al., 2012; Shipley \& Meziane, 2002). Plants will allocate more resources to root growth if the limiting factor is below-ground (e.g. nutrients, water) and more resources to shoot growth if the limiting factor is light (Fazlioglu, Al-Namazi, \& Bonser, 2016; Freschet, Violle, Bourget, Scherer-Lorenzen, \& Fort, 2018). The ecological advantage of this functional response is clear; by allocating more resources to the plant organ acquiring the most limiting resource, plants are able to acquire the needed resources for growth and reproduction. However, the timing of these responses is critical. For example, plants subjected to moderate levels of moisture stress show little to no changes in size and root mass. However, once plants are subjected to severe moisture stress biomass is reduced by $>$ $50 \%$, and allocation to roots increases strongly at the expense of shoot growth (Padilla, Miranda, Jorquera, \& Pugnaire, 2009). Plants might not respond very strongly to relatively short periods of moisture stress 
because of the unpredictability of precipitation. Increasing allocation to roots too quickly might result in suboptimal growth after the restoration of the water supply (Poorter et al., 2012). This is also true for other environmental responses, such as stem elongation responses light cues of neighbor proximity (Smith, 1992; Smith \& Whitelam, 1997; Weinig \& Delph, 2001).

One particularly important environmental cue with economic consequences, i.e. early allocation vs. later growth tradeoffs, is shade. Light reflected by green vegetation has a reduced ratio of red (R) to far-red (FR) light. Low R:FR thus provides a reliable cue of neighboring plants that may impose future competition for light and specifically competition for light wavelengths for photosynthesis. Exposure to light with a low R:FR ratio results in a series of developmental changes that serve to circumvent being shaded by other plants. These changes are collectively referred to as shade avoidance syndrome (McLaren \& Smith, 1978; Smith \& Whitelam, 1997; Weinig \& Delph, 2001; Whitelam \& Smith, 1991).

The developmental changes set off by shade-avoidance response (SAR) include differential allocation to roots, seeds, and leaves (Page et al., 2010; Schambow, Adjesiwor, Lorent, \& Kniss, 2019). When these effects are combined, crops exhibiting the shade avoidance syndrome in response to weeds constitute a potentially significant source of yield loss in agriculture (Page et al., 2012). We have previously shown that leaf number is reduced by season-long shade avoidance cues in three different sub-species of B. vulgaris . The reduction in number of leaves resulted in reduced leaf area and biomass (Schambow et al., 2019). In the current study, we experimentally manipulated the duration of the shade avoidance cue to assess the mechanism by which B. vulgaris growth is reduced. Specifically, we wanted to test whether shade avoidance cues during the early and late stages of $B$. vulgaris growth have the same effects on morphology and growth. It has long been known that early emerging weeds (weeds that emerge with the crop) have more detrimental impact on crop yield than late-emerging weeds (Dew, 1972; O'Donovan, Remy, O'Sullivan, Dew, \& Sharma, 1985; Swanton et al., 1999). In corn, $5 \%$ of potential yield is lost within 183 growing degree days (corresponding to 3 to 5 leaf stage) after planting due to weeds (Page et al., 2012).

It is logical to ascribe this phenomenon to the reduced crop growth from early-season resource depletion from weed competition. However, root interaction and growth resource (e.g. water, nutrients, and light) competition is very minimal early in the growing season. Thus, growth reduction from early-season weed presence could be due to other competitive effects of weeds rather than resource depletion. Rajcan, Chandler, and Swanton (2004) found that corn seedlings detected changes in light quality caused by the presence of grass (which was used to simulate low-growing weeds) and responded by adjusting carbon allocation and leaf orientation to optimize the light interception. Studies have shown that stem and petiole extension and hyponasty are among the most common SARs (Cerrudo et al., 2017; Franklin \& Whitelam, 2005; Yang \& Li, 2017). We hypothesize that early-season reflected FR light from neighboring weeds would induce hyponasty and increase allocation to petiole extension growth, thereby reducing root biomass of sugar beet. To test this hypothesis, we used a study design that prevents any direct resource competition, making it possible to assess the sole effect of reflected light on sugar beet growth. The understanding of shade avoidance responses in sugar beet and the role shade avoidance cues plays in yield loss during weed competition could provide novel insights into the critical period for weed control in this crop.

\section{Materials and methods}

\subsection{Experimental site and design}

Field and greenhouse studies were conducted from 2015 to 2019 at the University of Wyoming Laramie Research and Extension Center (LREC), Laramie, WY. The study comprised 12 weed removal or addition timing (growing degree days [GDD]) treatments in 2015 and 2016 and nine treatments in 2018 and 2019 (Table 1). The study was also conducted in 2017, but severe weather events and an irrigation system failure led to uneven emergence and heavy losses of experimental units, so the 2017 data were excluded from the analysis.

The large-pail design used by Green-Tracewicz, Page, and Swanton (2011) and modified by (Schambow et al., 2019) was used in these studies (Figure 1). This approach prevents any direct resource competition, 
making it possible to assess the sole effect of reflected light on sugar beet growth. Briefly, $19 \mathrm{~L}$ black plastic pails were filled with a potting mix (Berger, BM Custom Blend, Saint-Modeste, QC Canada) leaving about $7.5 \mathrm{~cm}$ head-space. A cardboard tube $(10 \times 122 \mathrm{~cm}$ Staples Kraft Heavy-Duty Mailing Tube: Staples Inc., Framingham, MA) of height $7.5 \mathrm{~cm}$ and $10 \mathrm{~cm}$ diameter was taped (Black Gorilla Tape: Gorilla Glue Co., Cincinnati, Ohio, USA) to a 2-mL white plastic bag and laid on top of the potting mix such that the cardboard tube was in the middle of the pail and flush with the rim of the pail. The plastic prevented roots of the weed from interacting with sugar beet roots (Figure 1). Potting mix was then added onto the plastic and into the cardboard tube.

Three sugar beet seeds (cultivar "BTS60RR27" in 2015 and 2016 and "RR014GEM50" in 2018 and 2019) were planted per pail in the center of the cardboard tube on July 3, 2015; May 31, 2016; June 1, 2018; and June 3, 2019. Emerged seedlings were thinned to one seedling per pail immediately after emergence. Sod of Kentucky bluegrass (Poa pratensis L.), was used to simulate low-growing weeds and planted around the cardboard tube in the weedy treatments (Figure 1).

The treatments were grouped into early-season and late-season treatment series (Table 1). The early-season series included treatments with weeds present at sugar beet emergence and then removed later in the growing season. The late-season series included treatments in which weeds were added at various times during the season and allowed to remain until sugar beet harvest. Treatments were arranged in a randomized complete block with 15 blocks in 2015 and 2016 and 27 blocks in 2018 and 2019.

Growing degree days (GDD) were estimated from daily minimum and maximum temperature [Eqn. 1], where $T_{\max }$ is the daily maximum temperature $\left({ }^{\circ} \mathrm{C}\right), T_{\min }$ is the daily minimum temperature $\left({ }^{\circ} \mathrm{C}\right)$, and $T_{\text {base }}$ is the base temperature of $1.1{ }^{\circ} \mathrm{C}$ (Holen \& Dexter, 1997; NDAWN Center, 2020). The first weed removal (early-season series) and first weed addition (late-season series) timings corresponded to the sugar beets reaching the two true-leaf stage, which occurred between 297 to 365 GDD after planting, depending on the year (Figure 2). Final harvest occurred between 1181 and 1240 GDD after sugar beet planting.

$G D D=\left(\frac{T_{\max }-T_{\min }}{2}\right)-T_{\text {base }}[1]$

Sugar beet was drip irrigated daily until maturity to ensure no yield limitation due to moisture stress. The model weed was also drip-irrigated separately to ensure green growth and optimal reflection of FR light. Sugar beet was fertilized with 85 g pail $^{-1}$ of 14:14:14:5.5\% (N:P:K:S) polymer-coated fertilizer (Florikote ${ }^{\mathrm{TM}}$ NPK, Florikan E.S.A.-LLC, Sarasota, FL) at planting to ensure slow and continuous release of nutrients throughout the growing season. The model weed was clipped regularly to prevent direct competition for sunlight.

Using the same experimental system, a greenhouse study was conducted from Nov 11, 2018, to Feb 5, 2019. Day and night temperatures were maintained at 22 and $20{ }^{\circ} \mathrm{C}$, respectively. No supplemental light was used, and plants were overhead irrigated twice a day throughout the experiments. The greenhouse study did not include the addition or removal treatments and comprised only two treatments: sugar beet surrounded by grass or no grass (weed-free), to enable detailed leaf measurements under controlled conditions.

\subsection{Data collection}

Number of leaves was measured weekly after seedling emergence. Leaf angle (from the soil horizon) of the oldest, healthiest leaf was measured using a protractor between 648 to 760 GDD (41 to 49 days after planting), depending on the year. The angle of the oldest leaves was measured because it was not possible to measure the angle of younger leaves without breaking the older leaves. Also, the angle of the younger leaves depends on the angle or position of the older leaf. Thus, the angle of the healthy older leaf provided a good estimate of the plant leaf angle. Sugar beet plants from the field study were harvested on September 16, 2015; August 10, 2016; August 14, 2018; and August 19, 2019. At harvest, leaves were separated from the roots, and roots were washed to remove potting media. Leaves were counted, and total leaf area per plant was measured by feeding leaves through an LI-3100C (LI-COR Inc., Lincoln, Nebraska, USA), respectively. Leaves were then dried at $60 \mathrm{C}$ for 48 hours and weighed to obtain shoot biomass per plant. Roots were sliced (to speed 
drying) and dried for 72 hours at $60 \mathrm{C}$ then weighed to obtain root biomass per plant.

In the greenhouse study, plants were harvested on Feb 5, 2019, and the leaves were separated from the crown according to the order of appearance or developmental stage (i.e according to phyllotaxy). The oldest leaf pair were assigned position numbers one and two, the second oldest leaf pair assigned position numbers three and four, and so forth. Thus, a lower leaf position corresponds to an older leaf and higher leaf position corresponds to a younger leaf at the time of harvest. Length of each leaf and petiole was measured using a ruler, and leaf width (at the widest part of the lamina) and leaf area were measured using a leaf area meter (LI-3100C, LI-COR Inc., Lincoln, Nebraska, USA).

\subsection{Data analyses}

A nonlinear mixed-effects model (4-parameter log-logistic function) was fit to the data and compared with the linear mixed-effects model using Akaike's Information Criterion (AIC). In all cases (except for leaf angle), the linear model provided a similar (AIC values within 10) or better (linear model AIC $<$ nonlinear model AIC) fit to the data than the nonlinear model. The nonlinear model was of the form

$$
f(x)=c+\frac{d-c}{1+e^{b(\log (x)-\log (e))}}
$$

where $x$ is the duration of weed-free or weedy GDD after planting; $f(x)$ is the leaf angle as a function of GDD after planting; $d$ and $c$ are upper and lower limits, respectively, indicating the estimated leaf angle at extreme values of $x ; b$ is the slope at the inflection point of the curve; and $e$ is the value of $x$ at which the inflection point occurs. The medrc package (Gerhard \& Ritz, 2016) in the R statistical language was used to fit nonlinear models, with random components included for the $c, d$, and eparameters.

A linear mixed-effects ANOVA was performed in R statistical language using the lmer function of the lme4 package (v1.1-23) and convenience functions from the lmerTest package (v.3.1-0) (Kuznetsova, Brockhoff, \& Christensen, 2017; R Core Team, 2020). Weed removal timing (early-season series) or addition timing (lateseason series) were considered fixed effects, and year was considered a random effect. An indicator variable was included in the analysis for each response variable, with a value of 1 for the weed-free treatment or a value of 0 for one of the addition or removal timings; each fixed effect (linear effect of addition or removal, and the weed-free indicator) was dropped from the model and the full and reduced models were compared with an F-test. If removal of an effect resulted in a significant reduction in model fit compared to the full model $(\mathrm{P}<0.1)$, then that effect was retained in the final model. In this way, if there was a significant effect of the indicator variable, but no significant effect of the removal or addition timing, then the effect was assumed to be attributable to only the presence of weeds during early sugar beet development, and not to the duration of weed presence beyond that period. Conversely, if there was an effect of addition or removal timing, but no effect of the weed-free indicator variable, then the response was attributed to the linear duration of weed presence.

Two-sample t-tests were used to compare the season-long weed-free treatment to season-long weedy treatments in the greenhouse study for final number of leaves, number of senesced leaves at harvest, and plant biomass. The $95 \%$ confidence intervals at each leaf pair were used as a conservative estimate of statistical difference between the season-long weed-free vs season-long weedy treatments (Austin \& Hux, 2002). A nonparametric local regression (loess) was fit to petiole proportion of leaf length as a function of leaf age for the greenhouse study.

\section{Results}

3.1 Shade avoidance cues at sugar beet emergence and the duration of shade avoidance cues added later affected sugar beet growth and development

When the shade avoidance cue was present at sugar beet emergence (early-season removal series), the effect of the weed-free indicator variable $(\mathrm{P}=0.065)$ and the linear effect of weed duration $(\mathrm{P}<0.001)$ impacted 
sugar beet leaf number at harvest, suggesting a substantial drop in leaf number from the early season weed exposure, but continuing effects as the shade avoidance cue remained throughout the season (Table 2). However, reductions in sugar beet leaf area, leaf biomass and root biomass were attributable to the presence of weeds through the two true-leaf stage $(\mathrm{P}<0.001)$. Once adjusted for the weed-free vs weedy treatment comparison, there was no effect of weedy duration in the early-season removal series $(\mathrm{P}>0.42)$, suggesting the duration of weed presence beyond the 2 true-leaf stage had minimal effect. In contrast, when the shade avoidance cue was added after the sugar beet 2 true-leaf stage, duration of weed presence had a significant effect on sugar beet growth reduction.

\subsection{Shade avoidance cues shortly after emergence irreversibly affect leaf development}

Sugar beet leaf angle was affected by the duration of weed presence (Figures 3 A \& B). In the presence of weeds, sugar beet had greater leaf angles (hyponastic; Figure 4), especially when weeds were present at sugar beet emergence (Figure 3A). Similarly, late-emerging weeds impacted leaf angle (Figure 3B), although the relationship between duration of weed presence and leaf angle was nonlinear; where weeds emerging before 500 GDD resulted in leaf angles similar to the season-long weedy treatment and weeds emerging after 500 GDD resulted in leaf angles similar to the season-long weed-free treatment (Figures 3B).

Early-season exposure to weeds had a season-long impact on sugar beet leaf number and leaf area, even if the weeds were removed at the two true-leaf stage ( $\sim 330$ GDD). Weeds present from sugar beet emergence to 330 GDD reduced leaf number by $10 \%$ (25.8 to 23.3 leaves per plant; Figure 3C) and reduced leaf area by $22 \%$ (3576 to $2786 \mathrm{~cm}^{2}$; Figure 3E). Season-long weed presence had no additional effect on sugar beet leaf area compared to the early-season weed presence but reduced the number of leaves by an additional $7 \%$ compared to removal at the two true-leaf timing (23.3 to 21.6 leaves per plant). There was a positive linear relationship between the duration of weed-free period and sugar beet leaf number and leaf area in the late-season weed addition series (Figure 3D, 3F). Compared to the season-long weed-free treatment, weeds added at the sugar beet two true-leaf stage ( $\sim 330 \mathrm{GDD})$ and remaining until the end of the growing season ( 1240 GDD) reduced leaf number by $12 \%$ (25.5 to 22.4$)$ and leaf area by $18 \%\left(3555\right.$ to $\left.2929 \mathrm{~cm}^{2}\right)$.

3.3 Season-long shade avoidance has less effect on the earliest developing leaves compared to leaves that develop later

In the greenhouse study, season-long weed presence reduced sugar beet leaf width (Figure 3A), leaf area (Figure 5B), petiole and whole leaf length (Figure 5C, 5D), which confirmed the field study results. Differences in sugar beet leaf width, leaf area, or total leaf length were not apparent on the oldest four leaves (leaf pairs 1 and 2) but were evident on the third and subsequent leaf pairs. Differences in petiole length between grass and no-grass treatments were evident on nearly all leaves (Figure 5C). Petiole proportion (petiole length/whole leaf length) was greater in the weed-free treatment for all leaf positions (Figure 5E), but the differences between treatments were more pronounced in the younger leaves (leaf pairs $>5$ ). For example, there was $9 \pm 2 \%$ difference in leaf area between the season-long weed presence and season-long weed-free treatment leaf pairs [?]4 and $42+-11 \%$ difference for leaf pairs $>4$ (Figure 5B).

\subsection{Early exposure to shade avoidance cues reduces leaf and root biomass production}

In the greenhouse study, the presence of weeds at sugar beet emergence until harvest reduced leaf biomass by $35 \%$ ( 15.5 to $10.0 \mathrm{~g}, \mathrm{P}$-value $=0.005)$ and root biomass by $32 \%(6.5$ to $4.4 \mathrm{~g}, \mathrm{P}$-value $=0.0002)$, and maintained the root to shoot biomass ratio for both treatments $(\mathrm{P}$-value $=0.57)$. The leaf biomass reduction is a function of both fewer leaves developing (19.7 in the weed-free treatment compared to 15.9 in the weedy treatment, P-value $=0.0002$ ), as well as smaller leaves (Figure 5). More leaves had senesced in the weed-free treatment compared to the weedy treatment $(2.8$ and 1.7 , respectively, P-value $=0.02)$.

In the field study, reduction in biomass was entirely attributable to the early presence of the shade avoidance cues. Presence of weeds at sugar beet emergence reduced leaf and root biomass by 25 and $32 \%$, respectively, even if weeds were removed as early as the 2-true leaf stage ( $~ 330$ GDD) (Figure 6A, 6C). Longer duration of weed presence after the 2 true-leaf stage did not reduce biomass further. In the late-season series, when 
weeds were added at the sugar beet two true-leaf stage and remained until harvest, sugar beet leaf biomass was reduced $18 \%$ and root biomass was reduced $23 \%$ compared to the weed-free control (Figure 6B, 6D). The biomass lost from weed addition in the late-season series followed a linear trend; for every 100 GDD that the sugar beets were kept weed-free, root yield increased by $3.8 \%$ compared to the season-long weedy treatment (Figure $6 \mathrm{D})$.

\section{Discussion}

Results from this study showed that shade avoidance cues from early emerging weeds (weeds that emerge with the sugar beet) have a more detrimental impact on sugar beet growth and development than late-emerging weeds. Sugar beet responded to an early shade avoidance cue by adjusting leaf orientation (hyponasty) to optimize light interception (Figure 3 and 4). Even when the weed was removed, the hyponastic response remained. These responses result in a reduced number of leaves and reduced leaf area for light capture and photosynthesis (Figure 3), thereby reducing shoot and root biomass (Figure 6). These results suggest a constitutive response where most, or even all, of the season-long shade avoidance response (SAR) in sugar beet growth is fixed by the time the sugar beet crop has reached the two true-leaf stage (approximately 330 GDD after planting). Removing weeds after that time had a small impact on the number of sugar beet leaves, but did not allow recovery of leaf area or biomass production, indicating that a constitutive shade avoidance response (CoSAR) may play a key role in crop yield loss due to weeds.

Studies have shown that stem and petiole extension and hyponasty are among the most common SARs (Cerrudo et al., 2017; Franklin \& Whitelam, 2005; Yang \& Li, 2017). Leaf orientation is an important factor influencing light interception in plants. This is because leaf angle relative to the direction of sunlight determines both the photosynthetic performance of the leaves at the top of the canopy as well as the amount of light available to lower leaves (Van Zanten, Pons, Janssen, Voesenek, \& Peeters, 2010). At the canopy level, steeper leaf angles reduce mutual shading and thus, maximize light interception (Mullen, Weinig, \& Hangarter, 2006). Since reduced R:FR is a cue for impending competition, it is not surprising that hyponasty is an intrinsic part of the shade avoidance syndrome (Van Zanten et al., 2010). Sugar beet has a rosette growth habit in the first season of growth and thus, hyponasty appears to be the strategy for projecting leaves for optimal light interception. We observed shade avoidance-induced hyponasty in the form of increased leaf angles in our study (Figure 3 and 4); however, sugar beet did not increase petiole or leaf length in response to shade avoidance cues as might be expected. In fact, we observed a reduction in petiole length, total leaf length, and petiole proportion of leaves in response to season-long shade avoidance cues in our greenhouse study (Figure 5).

Previous studies have found that reduced R:FR resulted in fewer leaves in A. thaliana (Xie et al., 2017) maize (Page, Liu, Cerrudo, Lee, \& Swanton, 2011), and soybean (Green-Tracewicz, Page, \& Swanton, 2012). We have previously shown that leaf number is reduced by season-long shade avoidance cues in three different sub-species of $B$. vulgaris (Schambow et al., 2019). Here, we show that although the first two leaf pairs were least affected with respect to leaf size and area (Figure 5), subsequent sugar beet leaf development was reduced substantially even if weeds were removed early in plant development (Figure 3). Compared to season-long weed-free treatments in this study, the number of sugar beet leaves were reduced $10 \%$ if weeds were present for the first 16 days after emergence, and only reduced $12 \%$ if weeds were added 16 days after emergence and remained for the next 51 days (the average time from two true-leaf stage to harvest in this study). Early-emerging weeds have more impact on sugar beet leaf development compared to late-emerging weeds.

The relationship between sugar beet leaf area (Figure $3 \mathrm{E} \& \mathrm{~F}$ ) and the duration of weed presence follows a similar trend as number of leaves, with early presence of the shade avoidance cue initiating an irreversible season-long response. Since leaf area is a function of leaf size and number, it appears the reduction in sugar beet leaf area was at least partly due to reduced number of leaves. Results from the greenhouse study showed that, in addition to reduced number of leaves, reflected FR light reduced sugar beet leaf width, petiole length, and total leaf length as well (Figure 5). Differences in sugar beet leaf size were most pronounced after the first six true-leaves had appeared, which corresponds to the transition from leaf canopy-dominated growth 
to root cambium development (followed by storage root and sugar accumulation dominated phase) (Milford, 2006). Most capacity for storage root size and weight is laid down by the sixth true leaf stage (Milford, 2006).

Although increased petiole elongation is a common response to shade avoidance cues (Weijschede, Martinkova, De Kroon, \& Huber, 2006), we observed a reduction in petiole length (Figure 5C), even as a proportion of total leaf length (Figure $5 \mathrm{E}$ ), from sugar beet plants exposed to weed-reflected light in the greenhouse study. Sugar beet did not increase petiole length in response to shade avoidance cues as we had predicted based on previous work in other plant species. This illustrates the importance of conducting research on crop species with different growth habits, rather than generalizing from more commonly studied species like Arabidopsis, maize, and soybean.

The reduction in sugar beet leaf size and leaf number reduced leaf biomass, and subsequently, reduced root biomass (Figure 6). It is clear from our results that weeds present at sugar beet emergence had a significantly greater impact on sugar beet growth compared to weeds added later in the season. Many previous studies have also shown that early emerging weeds have a substantial effect on sugar beet yield. Early weed removal is often recommended in sugar beets (Jalali \& Salehi, 2013). Our results demonstrate that a substantial portion of reduced yield due to weeds may be due to shade avoidance, rather than solely resource depletion as is commonly thought. To protect sugar beet yield potential, ensuring a weed-free environment at emergence may be critical.

It is important to state that crop yield loss due to shade avoidance is typically understood in the context of consistent FR light stimulation, but our understanding of shade avoidance responses at the molecular level is not well-connected to whole-plant responses in agronomically relevant contexts (Guo et al., 2017; Shikata et al., 2014). Alternative splicing occurs in response to far-red light at the seed stage, and changes development into the seedling stage, but the effects on further growth are not well understood after this point (Penfield, Josse, \& Halliday, 2010; Shikata et al., 2014). There is evidence that phytochrome interacting factor (PIF) proteins are upregulated specifically in response to weed competition, although these do not occur in all species (Horvath et al., 2019; Horvath et al., 2015; Page, Tollenaar, Lee, Lukens, \& Swanton, 2009). The gene which controls leaf area index (LAI) during the shade avoidance response is also involved in growth-phase transition and thus, can affect organ size and whole-plant biomass (Fu et al., 2012; Toriba et al., 2019; Wang, Schwab, Czech, Mica, \& Weigel, 2008; Wu et al., 2009; Xie et al., 2017). This latter observation is particularly intriguing in light of differential leaf area development shown in Figure 3 , that a CoSAR can play a significant role in crop yield loss opens a potential pathway for improved breeding and bioengineering strategies.

We conclude that sugar beet exhibits a constitutive shade avoidance response when exposed to early-emerging weeds causing season-long impacts that affect growth, development, and yield potential. Thus, this work has significant practical implications for weed management (e.g. timing of weed removal) as well as crop genetic improvement. However, our study system ensured a strong reflected R:FR light ratio at the time of sugar beet emergence, and the weed density or proximity of weeds to the sugar beet plants required to cause a similar response under more typical field conditions remains unknown. This will no doubt vary by weed species [e.g. differences in reflectance, growth habit (erect vs prostrate), etc], crop row spacing, and other agronomic factors. Although it is uncommon for weeds to be extremely dense in the field at the time of sugar beet emergence, there is growing interest in 'planting green', where a cash crop is seeded directly into established cover crops, and this work suggests that practice may have unforeseen impacts on crop yield potential.

\section{References}

Austin, P. C., \& Hux, J. E. (2002). A brief note on overlapping confidence intervals. Journal of vascular surgery, 36 (1), 194-195.

Cerrudo, I., Caliri-Ortiz, M. E., Keller, M. M., Degano, M. E., Demkura, P. V., \& Ballare, C. L. (2017). Exploring growth-defence trade-offs in Arabidopsis: phytochrome B inactivation requires JAZ10 to suppress 
plant immunity but not to trigger shade-avoidance responses. Plant Cell and Environment, 40 (5), 635-644. doi:10.1111/pce.12877

Dew, D. (1972). An index of competition for estimating crop loss due to weeds. Canadian Journal of Plant Science, 52 (6), 921-927.

Fazlioglu, F., Al-Namazi, A., \& Bonser, S. P. (2016). Reproductive efficiency and shade avoidance plasticity under simulated competition. Ecology and Evolution, 6 (14), 4947-4957.

Franklin, K. A., \& Whitelam, G. C. (2005). Phytochromes and shade-avoidance responses in plants. Annals of botany, 96 (2), 169-175.

Freschet, G. T., Violle, C., Bourget, M. Y., Scherer-Lorenzen, M., \& Fort, F. (2018). Allocation, morphology, physiology, architecture: the multiple facets of plant above-and below-ground responses to resource stress. New Phytologist, 219 (4), 1338-1352.

Fu, C., Sunkar, R., Zhou, C., Shen, H., Zhang, J. Y., Matts, J., . . . Tang, Y. (2012). Overexpression of miR156 in switchgrass (Panicum virgatum L.) results in various morphological alterations and leads to improved biomass production. Plant biotechnology journal, 10 (4), 443-452.

Gedroc, J., McConnaughay, K., \& Coleman, J. (1996). Plasticity in root/shoot partitioning: optimal, ontogenetic, or both? Functional Ecology, 44-50.

Gerhard, D., \& Ritz, C. (2016). medrc: Mixed effect dose-response curves. R package version 0.0-75.

Green-Tracewicz, E., Page, E., \& Swanton, C. (2011). Shade avoidance in soybean reduces branching and increases plant-to-plant variability in biomass and yield per plant. Weed Science, 59 (1), 43-49.

Green-Tracewicz, E., Page, E., \& Swanton, C. (2012). Light quality and the critical period for weed control in soybean. Weed Science, 60 (1), 86-91.

Guo, D., Song, X., Yuan, M., Wang, Z., Ge, W., Wang, L., . . . Wang, X. (2017). RNA-Seq profiling shows divergent gene expression patterns in Arabidopsis grown under different densities. Frontiers in plant science, 8, 2001.

Holen, C. D., \& Dexter, A. G. (1997). A growing degree day equation for early sugarbeet leaf stages. Sugarbeet Research and Extension Reports, 27 , 152-157.

Horvath, D. P., Clay, S. A., Bruggeman, S. A., Anderson, J. V., Chao, W. S., \& Yeater, K. (2019). Varying Weed Densities Alter the Corn Transcriptome, Highlighting a Core Set of Weed-Induced Genes and Processes with Potential for Manipulating Weed Tolerance. The Plant Genome, 12 (3), 1-9.

Horvath, D. P., Hansen, S. A., Moriles-Miller, J. P., Pierik, R., Yan, C., Clay, D. E., . . . Clay, S. A. (2015). RNA seq reveals weed-induced PIF 3-like as a candidate target to manipulate weed stress response in soybean. New Phytologist, 207 (1), 196-210.

Jalali, A. H., \& Salehi, F. (2013). Sugar beet yield as affected by seed priming and weed control.Archives of Agronomy and Soil Science, 59 (2), 281-288. doi:10.1080/03650340.2011.608158

Kuznetsova, A., Brockhoff, P. B., \& Christensen, R. H. B. (2017). lmerTest package: tests in linear mixed effects models. Journal of statistical software, 82 (13).

McLaren, J. S., \& Smith, H. (1978). Phytochrome control of the growth and development of Rumex obtusifolius under simulated canopy light environments. Plant, cell $\&$ environment, 1 (1), 61-67.

Milford, G. F. (2006). Plant structure and crop physiology. Sugar beet, 30-49.

Mullen, J. L., Weinig, C., \& Hangarter, R. P. (2006). Shade avoidance and the regulation of leaf inclination in Arabidopsis. Plant, cell $\mathscr{E}$ environment, 29 (6), 1099-1106. 
NDAWN Center. (2020). Sugarbeet growth stage development and growing degree day accumulation. [North Dakota Agricultural Network Center]. Retrieved from https://ndawn.ndsu.nodak.edu/helpsugarbeet-growing-degree-days.html

O'Donovan, J. T., Remy, E. A. d. S., O'Sullivan, P. A., Dew, D. A., \& Sharma, A. K. (1985). Influence of the relative time of emergence of wild oat (Avena fatua) on yield loss of barley (Hordeum vulgare) and wheat (Triticum aestivum). Weed Science, 498-503.

Padilla, F. M., Miranda, J. D., Jorquera, M. J., \& Pugnaire, F. I. (2009). Variability in amount and frequency of water supply affects roots but not growth of arid shrubs.Plant Ecology, 204 (2), 261-270.

Page, E., Cerrudo, D., Westra, P., Loux, M., Smith, K., Foresman, C., . . . Swanton, C. (2012). Why early season weed control is important in maize. Weed Science, 60 (3), 423-430.

Page, E., Liu, W., Cerrudo, D., Lee, E., \& Swanton, C. (2011). Shade Avoidance Influences Stress Tolerance in Maize. Weed Science, 59 (3), 326-334. doi:10.1614/Ws-D-10-00159.1

Page, E., Tollenaar, M., Lee, E., Lukens, L., \& Swanton, C. (2009). Does the shade avoidance response contribute to the critical period for weed control in maize (Zea mays)? Weed Research, 49 (6), 563-571.

Page, E., Tollenaar, M., Lee, E., Lukens, L., \& Swanton, C. (2010). Shade avoidance: an integral component of crop-weed competition. Weed Research, 50 (4), 281-288.

Penfield, S., Josse, E.-M., \& Halliday, K. J. (2010). A role for an alternative splice variant of PIF6 in the control of Arabidopsis primary seed dormancy. Plant molecular biology, 73 (1-2), 89-95.

Poorter, H., Niklas, K. J., Reich, P. B., Oleksyn, J., Poot, P., \& Mommer, L. (2012). Biomass allocation to leaves, stems and roots: meta-analyses of interspecific variation and environmental control. New Phytologist, $193(1), 30-50$.

R Core Team. (2020). R: A language and environment for statistical computing. R Foundation for Statistical Computing. $\mathrm{R}$ version 4.0.2. In.

Rajcan, I., Chandler, K. J., \& Swanton, C. J. (2004). Red-far-red ratio of reflected light: a hypothesis of why early-season weed control is important in corn. Weed Science, 52 (5), 774-778.

Schambow, T. J., Adjesiwor, A. T., Lorent, L., \& Kniss, A. R. (2019). Shade avoidance cues reduce Beta vulgaris growth. Weed Science, 67 (3), 311-317.

Shikata, H., Hanada, K., Ushijima, T., Nakashima, M., Suzuki, Y., \& Matsushita, T. (2014). Phytochrome controls alternative splicing to mediate light responses in Arabidopsis.Proceedings of the National Academy of Sciences, 111 (52), 18781-18786.

Shipley, B., \& Meziane, D. (2002). The balanced-growth hypothesis and the allometry of leaf and root biomass allocation. Functional Ecology, 16 (3), 326-331.

Smith, H. (1992). The Ecological Functions of the Phytochrome Family - Clues to a Transgenic Program of Crop Improvement. Photochemistry and Photobiology, 56 (5), 815-822. doi:DOI 10.1111/j.17511097.1992.tb02238.x

Smith, H., \& Whitelam, G. C. (1997). The shade avoidance syndrome: Multiple responses mediated by multiple phytochromes. Plant Cell and Environment, 20 (6), 840-844. doi:DOI 10.1046/j.1365-3040.1997.d01104.x

Swanton, C., Weaver, S., Cowan, P., Acker, R. V., Deen, W., \& Shreshta, A. (1999). Weed thresholds: theory and applicability. Journal of Crop Production, 2 (1), 9-29.

Toriba, T., Tokunaga, H., Shiga, T., Nie, F., Naramoto, S., Honda, E., . . . Kyozuka, J. (2019). BLADEON-PETIOLE genes temporally and developmentally regulate the sheath to blade ratio of rice leaves. Nature communications, 10 (1), 1-13. 
Van Zanten, M., Pons, T., Janssen, J., Voesenek, L., \& Peeters, A. (2010). On the relevance and control of leaf angle. Critical Reviews in Plant Science, 29 (5), 300-316.

Wang, J.-W., Schwab, R., Czech, B., Mica, E., \& Weigel, D. (2008). Dual effects of miR156-targeted SPL genes and CYP78A5/KLUH on plastochron length and organ size in Arabidopsis thaliana. The Plant Cell, 20 (5), 1231-1243.

Weijschede, J., Martinkova, J., De Kroon, H., \& Huber, H. (2006). Shade avoidance in Trifolium repens: costs and benefits of plasticity in petiole length and leaf size.New Phytologist, 172 (4), 655-666.

Weinig, C., \& Delph, L. F. (2001). Phenotypic plasticity early in life constrains developmental responses later. Evolution, 55 (5), 930-936.

Whitelam, G. C., \& Smith, H. (1991). Retention of Phytochrome-Mediated Shade Avoidance Responses in Phytochrome-Deficient Mutants of Arabidopsis, Cucumber and Tomato.Journal of Plant Physiology, 139 (1), 119-125.

Wu, G., Park, M. Y., Conway, S. R., Wang, J.-W., Weigel, D., \& Poethig, R. S. (2009). The sequential action of miR156 and miR172 regulates developmental timing in Arabidopsis. Cell, 138 (4), 750-759.

Xie, Y., Liu, Y., Wang, H., Ma, X., Wang, B., Wu, G., \& Wang, H. (2017). Phytochrome-interacting factors directly suppress MIR156 expression to enhance shade-avoidance syndrome in Arabidopsis. Nature communications, 8 (1), 1-11. doi:10.1038/s41467-017-00404-y

Yang, C., \& Li, L. (2017). Hormonal regulation in shade avoidance. Frontiers in plant science, 8 , 1527. doi:10.3389/fpls.2017.01527

Table 1. Treatment descriptions showing the start and end of weed treatments in growing degree days (GDD)

\begin{tabular}{|c|c|c|c|c|}
\hline Timing & Start of weed treatment & Start of weed treatment & Start of weed treatment & Start of weed treatment \\
\hline \multirow{8}{*}{ Early series+ } & 2015 & 2016 & 2018 & 2019 \\
\hline & 0 & 0 & 0 & 0 \\
\hline & 0 & 0 & 0 & 0 \\
\hline & 0 & 0 & 0 & 0 \\
\hline & 0 & 0 & $0^{\S}$ & $0^{\S}$ \\
\hline & 0 & 0 & - & - \\
\hline & 0 & 0 & - & - \\
\hline & $0^{\S}$ & $0^{\S}$ & - & - \\
\hline \multicolumn{5}{|l|}{ Late series ${ }^{++}$} \\
\hline & 330 & 297 & 365 & 352 \\
\hline & 398 & 384 & 465 & 452 \\
\hline & 462 & 451 & 565 & 552 \\
\hline & 631 & 648 & 765 & 752 \\
\hline & $1181^{\mathbb{I}}$ & $1185^{\mathbb{I}}$ & $1240^{\mathbb{I}}$ & $1223^{\mathbb{I}}$ \\
\hline
\end{tabular}

+Early series treatments denote weed presence at sugar beet emergence;

${ }^{++}$Late series treatments weed addition after sugar beet emergence;

SS Weed presence from emergence to harvest (season-long weed presence)

${ }^{\mathrm{P}}$ Season-long weed-free treatment

Table 2. Model selection p-values for sugar beet leaf and root measurements from the field study. Null hypothesis is that removal of the fixed effect term (weedy vs non, duration) does not reduce model fit; significant P-values suggest the term should remain in the model. P-values associated with final selected model terms are printed in bold. 


\begin{tabular}{llll}
\hline & & P-value & P-value \\
Response variable & Treatment series & Weed-free vs weedy & Weedy duration \\
Leaf number & Early-season removal & $\mathbf{0 . 0 6 5}$ & $<\mathbf{0 . 0 0 1}$ \\
& Late-season addition & 0.280 & $<\mathbf{0 . 0 0 1}$ \\
Leaf area & Early-season removal & $\mathbf{< 0 . 0 0 1}$ & 0.704 \\
& Late-season addition & 0.975 & $<\mathbf{0 . 0 0 1}$ \\
Leaf biomass & Early-season removal & $\mathbf{< 0 . 0 0 1}$ & 0.832 \\
& Late-season addition & 0.641 & $<\mathbf{0 . 0 0 1}$ \\
Root biomass & Early-season removal & $<\mathbf{0 . 0 0 1}$ & 0.420 \\
& Late-season addition & 0.748 & $<\mathbf{0 . 0 0 1}$ \\
\hline
\end{tabular}

\section{Figure legends}

Figure 1. Illustration of the grass treatment used in the field experiment from the top-view (left) and a cross-section (right), modeled after (Emily Green-Tracewicz et al., 2011) as modified by (Schambow et al., 2019). Sugar beet was planted into the center ring, and was allowed to grow using the full depth $(35 \mathrm{~cm})$ of the 21-liter pail. Grass roots were constrained to the top $7.5 \mathrm{~cm}$ and outer $9 \mathrm{~cm}$ of the pail, and were isolated from the sugar beet roots using plastic. Grass was clipped as needed to minimize any direct shading of the sugar beet plant in the center. For the soil treatment, the design was the same, except no grass was planted into the potting media in the outer ring. Drawing by Jessica Perry.

Figure 2. Typical sugar beet growth porgession during the growing season. Growing degree days (GDD) calculated using the parameters described in Equation 1. The 240, 480, 720, 920, and 1200 GDD correspond to approximately 15, 30, 45, 75 days after planting sugar beet. Drawing by Jessica Perry.

Figure 3. Relationship between duration of weed presence and number of sugar beet leaf angle at $\sim 700$ growing degree days (GDD; $\sim 45$ days after planting) (A and B), number of leaves at harvest (C and D), and leaf area (E and F) in a field study conducted from 2015 to 2019, Laramie WY. Black lines show the fixed effects predictions, colored lines correspond to individual years. Panels on the left (A, C, and E) included treatments in which weeds were present at sugar beet emergence until removed later in the growing season. The dotted line in figure $\mathrm{C}$ and $\mathrm{E}$ indicate a break in the linear trend in the absence of the weed-free treatment. Panels on the right $(\mathrm{B}, \mathrm{D}$, and $\mathrm{F})$ included treatments in which weeds were added at various times during the season and allowed to remain until harvest. Regression equations are from the linear mixed-effects model. P-values in parenthesis are for the reduced model that did not include the season-long weed-free treatment.

Figure 4. Sugar beet shoot growth in the weed-free (left) and weedy (right) at 41 days (648 growing degree days) in the field experiment in 2016, Laramie WY.

Figure 5. Relationship between sugar beet leaf position and leaf width (A), leaf area (B), petiole length (C), leaf length (D), and petiole proportion of total leaf length (E) at harvest in a greenhouse study conducted from Nov 11, 2018, to Feb 5, 2019, Laramie WY. Leaf pair 1 indicates the oldest leaf pair. Bars and shaded area indicate $95 \%$ confidence intervals.

Figure 6. Relationship between duration of weed presence and sugar beet leaf biomass (A and B) and root biomass (C and D) in a field study conducted from 2015 to 2019, Laramie WY. Black lines show the fixed effects predictions, colored lines correspond to individual years. Panels on the left (A, C) included treatments in which weeds were present at sugar beet emergence until removed later in the growing season. The dotted line A indicates a break in the linear trend in the absence of the weed-free treatment. Panels on the right $(\mathrm{B}, \mathrm{D})$ included treatments in which weeds were added at various times during the season and allowed to remain until harvest. Regression equations are from the linear mixed-effects model. P-values in parenthesis are for the reduced model that did not include the season-long weed-free treatment. 

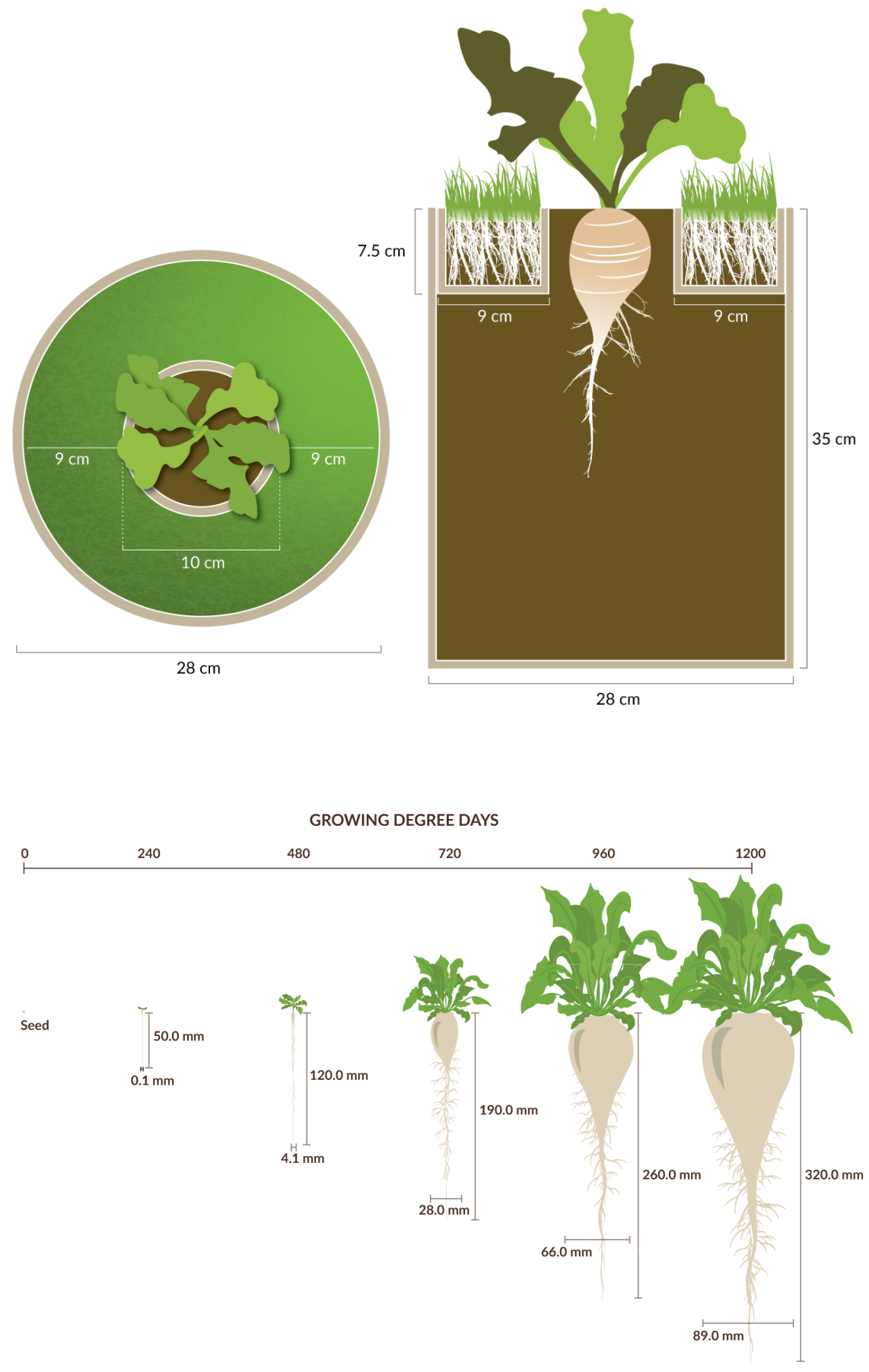

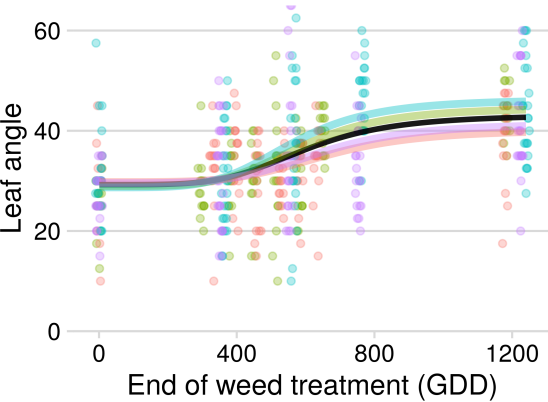

C $20152016=2018=2019$

60

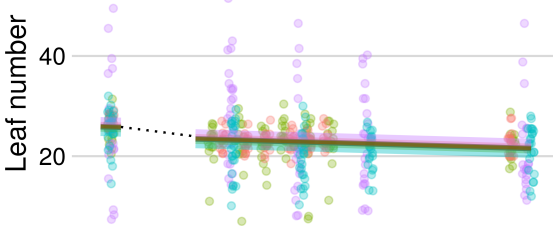

0

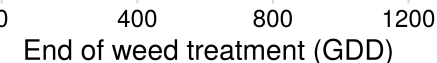

E

$2015=2016=2018=2019$ F

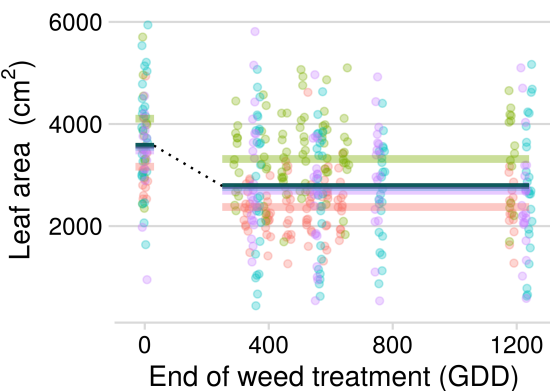

B $=2015=2016=2018=2019$

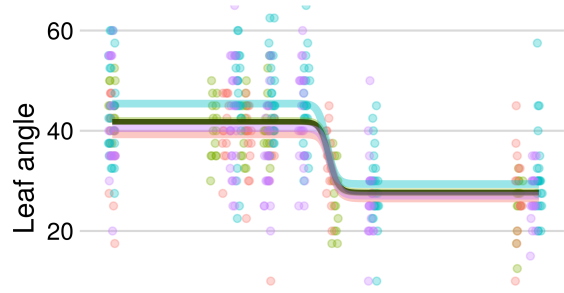

0

$0 \quad 400 \quad 800$

Start of weed treatment (GDD)

D

$2015=2016=2018=2019$

60

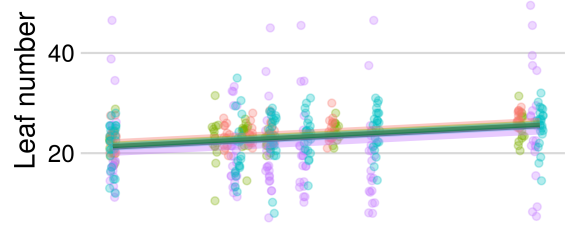

0

$\begin{array}{llll}0 & 400 & 800 & 1200\end{array}$ Start of weed treatment (GDD)

F $2015=2016=2018=2019$

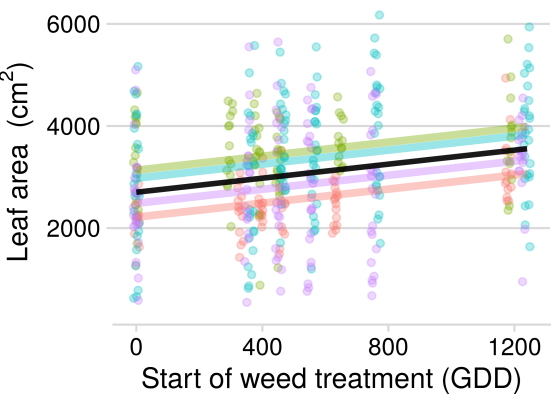



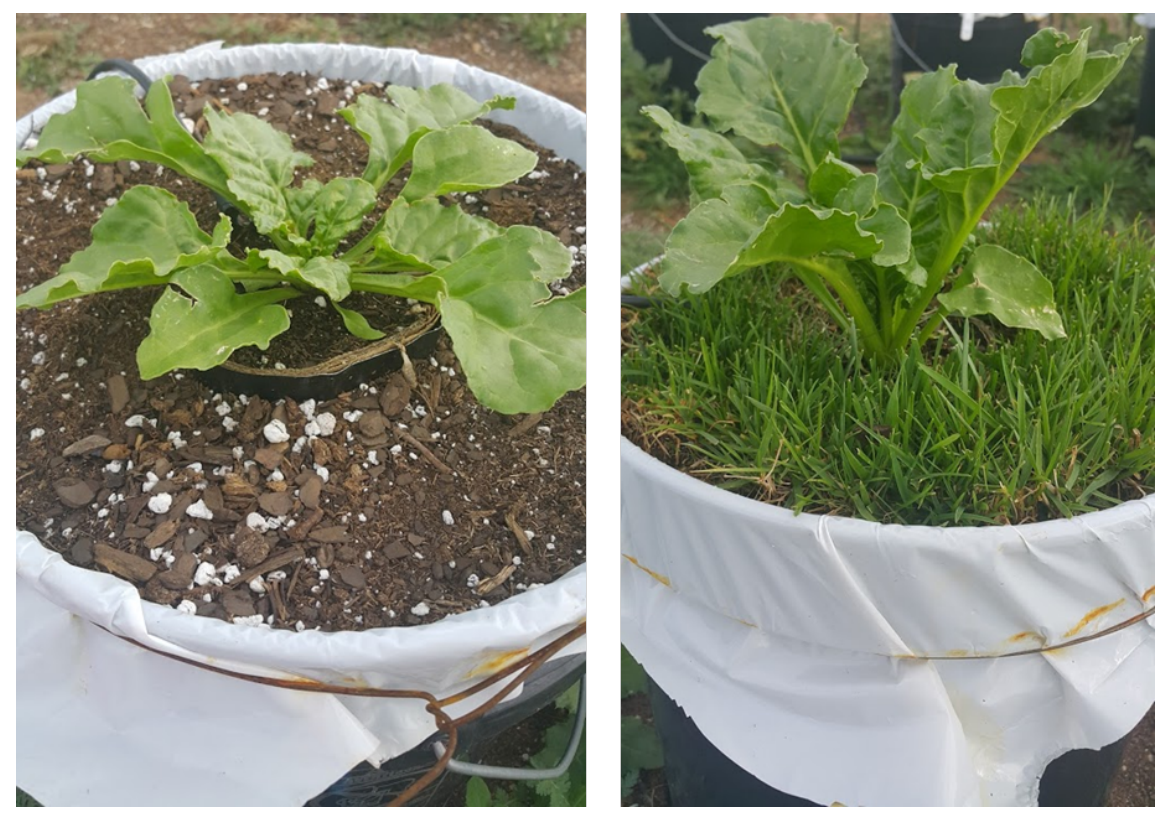

A 20
B 300
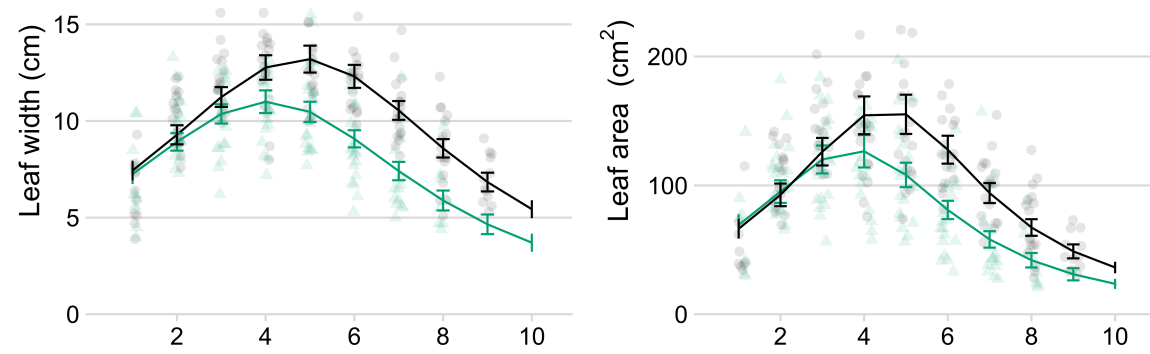

C 25

D 40

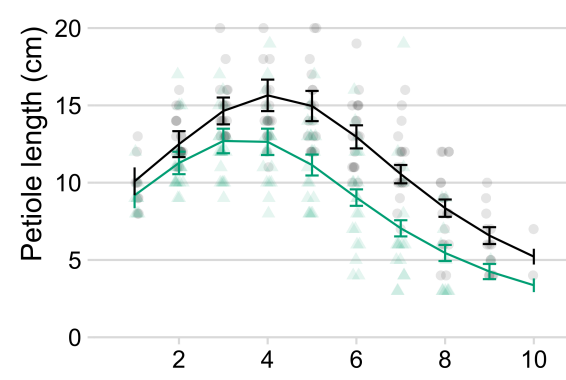

E 0.8
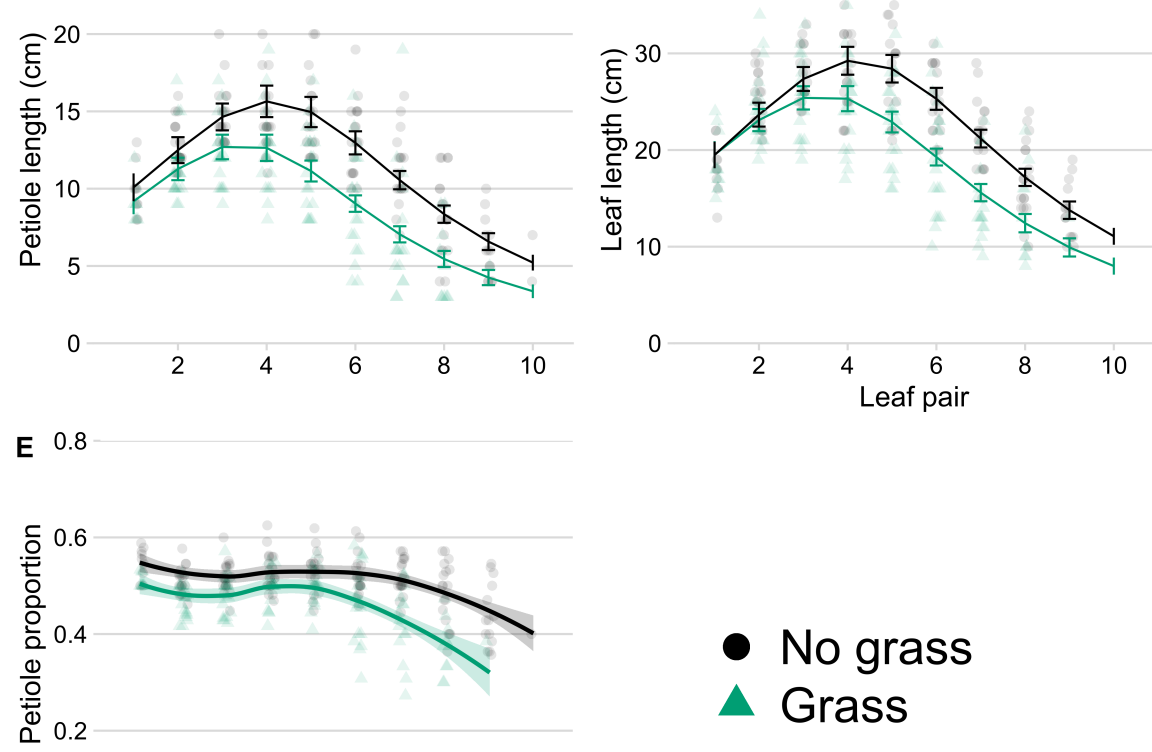

- No grass

- Grass

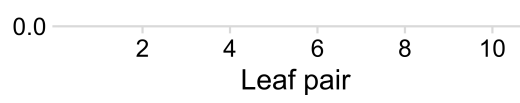




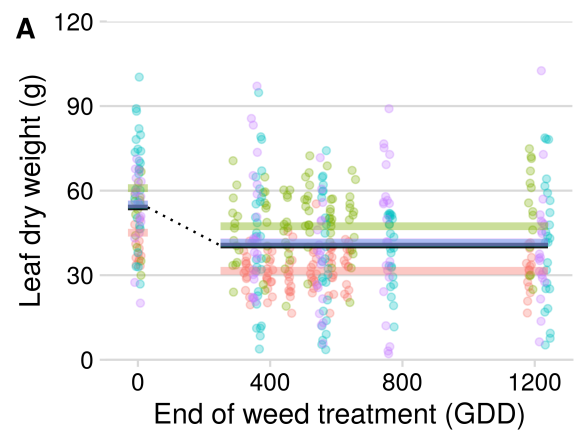

B 120

C

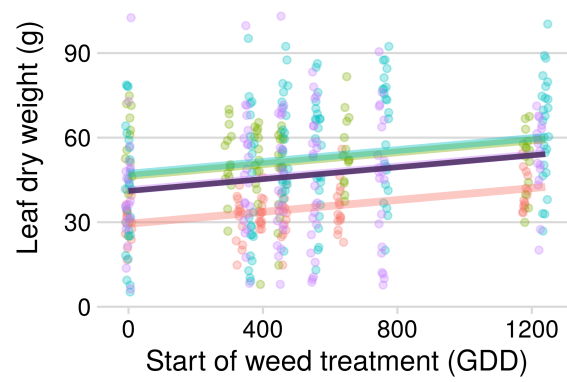

$=2015-2016-2018=2019$

D $\quad 2015=2016=2018=2019$
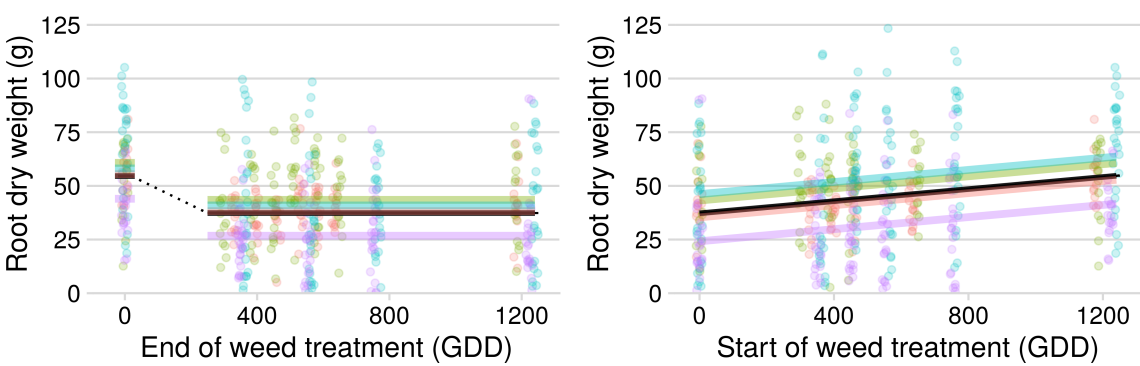